\title{
ПЕРЕОСМЫСЛЕНИЕ ПРЕДМЕТА АДМИНИСТРАТИВНОГО ПРАВА В СОВРЕМЕННЫХ УСЛОВИЯХ: РЫНОК ЦЕННЫХ БУМАГ И ГЛОБАЛИЗАЦИЯ ЭКОНОМИКИ
}

\begin{abstract}
Аннотация: Одной из ключевых категорий любой отрасли права является его предмет. Не является исключением и административное право. Административно-правовая наука неохотно обращается к вопросу об изменении состава общественных отношений, составляющих предмет административного права. Однако, изменения, происходящие в обществе, настоятельно требуют пересмотреть подходы к данному вопросу. Государство не может оставаться в стороне от регулирования экономики. Поэтому возникающие в этой сфере отношения не могут регулироваться исключительно гражданско-правовыми средствами. Все актуальней становится административно-правовое воздействие экономические отношения, в том числе в области обращуения цченных бумаг. При этом при формировании механизма административно-правового воздействия на экономические отношения должен учитываться фактор глобализации современной экономики. Именно данным проблемам посвящена настоящая статья.

Ключевые слова: Юриспруденция, Предмет административного права, Рынок иенных бумаг, Глобализация экономики, Эмиссионные ценные бумаги, Государственные и муниципальные ценные бумаги, Государственное управление в области обращчения цุенных бумаг, Экономические отношения, Акции, Облигаџии.
\end{abstract}

$\mathrm{P}$ ыночная экономика, развивающаяся циклично, что в условиях глобализации таит в себе как положительный, так и отрицательный потенциал. Это со всей очевидностью было продемонстрировано двумя последними финансово-экономическими кризисами: первый - 1998; первая волна второго пришлась на 2008-2010 гг. В преддверии наступления второй волны настоящего кризиса представители ведущих стран собрались в Давосе на Всемирный экономический форум, чтобы выработать меры по защите мировой экономики от негативных последствий подобных кризисов ${ }^{1}$. В числе рассматриваемых мер выступают и проблемы совершенствования административно-правового воздействия на экономические отношения, и сочетании мирового экономического правопорядка с национальными. Глобализация как текущий этап развития системы разделения труда, имеющая в своей основе объективные факторы, отталкиваясь от деятельности транснациональных корпораций, все больше перерастает в единство мирового рынка, что, с неизбежностью, ведет к интеграции национальных экономик, банковского сектора, страховых услуг, их правовой регламентации. Глобализация экономики, с неизбежностью, ведет к глобализации правового ре-

\footnotetext{
${ }^{1}$ Давос проблем // Российская газета. 2012. 27 января.
}

гулирования экономических отношений, ломая многовековые национальные традиции правотворчества и правоприменения. Применительно к административно-правовому регулированию, речь нужно вести не о противодействии этим процессам, а скорее о гармонизации, учитывая при этом, что разные экономические институты далеко не в равной степени способны к интернационализации, а часть из них априори тяготеют к национальному правопорядку.

В этой связи привлекает к себе внимание научная статья профессор С.В. Запольского «Глобализация экономики: финансово-правовой аспект» ${ }^{2}$, в которой этот маститный ученый в постановочном плане рассматривает возможности отечественного налогового, валютного, бюджетного права к международноправовой интеграции. Отмечая дихотомию правового регулирования в налоговом и валютном праве (резиденты и нерезиденты), Сергей Васильевич не относит это к порокам или ошибкам законодателя, а рассматривает это лишь как первые шаги в направлении полноценного участия России в мирохозяйственной системе, совершаемые в условиях неподготовленности общеправовой среды для такого участия и отсутствия

\footnotetext{
2 Запольский С.В. Глобализация экономики: финансово-правовой аспект. // Финансовое право. 2011. № 11. С. 2 - 6.
} 
сколь-нибудь значимого опыта 3 . По его мнению, институт публичного права и публичного долга, относящийся сейчас к бюджетному праву, должен получить собственную законодательную базу, как и институт государственных расходов. От себя добавим, что данные институты должны носить комплексный характер, соединяя в себе финансово-правовые и административно-правовые нормы.

Трансформация правовых основ функционирования банковской системы страны должна осуществляться с учетом набирающей силы в развитых странах тенденции придания коммерческим банкам публичноправовых функций. В заключении указанный автор констатирует, что «финансовое право, будучи частью публичного права, и в то же время, имея в качестве предмета регулирования имущественные, денежные отношения, обладает уникальной способностью создания юридических конструкций и механизмов, удовлетворяющих как публичные, так и частные интересы. Представляется, что глобализация экономического регулирования в нашей стране пойдет по пути повышения роли и расширении сферы применения финансового права и других публично-правовых институтов» ${ }^{4}$.

Вышеизложенные концептуальные подходы к рассмотрению публично-правовых аспектов глобализации экономики находят свое преломление относительно рынка ценных бумаг (фондового рынка).

Законодатель не дает легального определения понятия «рынок ценных бумаг». Поэтому в экономической и юридической литературе встречаются различные трактовки этой дефиниции. Так, в современном финансово-кредитном словаре рынок ценных бумаг рассматривается в качестве сегмента финансового рынка, на котором продаются-покупаются все виды ценных бумаг (фондовых инструментов), имитированных организациями, различными финансовыми институтами и государством 5 . В других экономических словарях рынок ценных бумаг трактуется как часть рынка ссудных капиталов, где осуществляется эмиссия, купля-продажа ценных бумаг ${ }^{6}$ Юристы в своих словарях трактуют рынок ценных бумаг как «совокупность отношений по поводу ценных бумаг, является одним

\footnotetext{
${ }^{3}$ Там же. С. 3.

${ }^{4}$ Там же. С. $5-6$.

5 Современный финансово-кредитный словарь / Под общ. ред. М. Г. Лагусты, П.С. Никольского. М., 2002. С. 412.

${ }^{6}$ Большой экономический словарь / Под ред. А.Н. Азрилиана. - 7-е изд. М., 2007. С. 1047.
}

из финансовых рынков», и рассматривают государственное регулирование применительно к трактовке закона «О рынке ценных бумаг» от 22 апреля 1996 г.. Представители гражданского и предпринимательского (хозяйственного) права рассматривают рынок ценных бумаг как сферу «обращения определенных видов ценных бумаг, осуществляемого по установленным правилам между обладающими правами и обязанностями субъектами» ${ }^{8}$, либо как сферу обращения ценных бумаг, обладающих свойствами специфического товара, в рамках определенной территории и по особым правилам между субъектами, осуществляющими или иным образов воздействующими на их выпуск, обращение и погашение 9 . Более кратко, как выразился Е.А. Суханов, под рынком ценных бумаг понимается «совокупность сделок, совершаемых участниками имущественного оборота по поводу ценных бумаг» ${ }^{10}$. Примечательно и то, что многие экономисты при определении ценной бумаги ссылаются на ее трактовку в ст. 142 ГК РФ, которая носит чисто юридический характер, в то время как с экономической точки зрения ценную бумагу стоит рассматривать как форму существования капитала, облегчающую его перераспределение, которая может обращаться на рынке и приносить доход.

Подобный подход был свойственен первоначальному этапу хозяйственных реформ, преследовавших становление и развитие рынка, где приоритет получило частное право. Однако в дальнейшем, как справедливо отмечает В.Ф. Яковлев, стало ясно, что в отсутствие эффективно функционирующего публичного права, частноправовые ценности работать не в состоянии ${ }^{11}$.

Пытаясь раскрыть суть рынка ценных бумаг, В.А. Белов рассматривает его как совокупность правовых и экономических отношений по поводу выпу-

\footnotetext{
7 Финансовый словарь. / Благодатин А.А., Лозовский Л.Ш., Райзберг Б.А. - М., 2009. С.230.

${ }^{8}$ Большой юридический словарь / Под. ред. А.Я. Сухарева, В.Д. Зорькина, В.Е. Крутских - М, 1999. С. 602.

${ }^{9}$ См.: Ершова И.В. Предпринимательское право. М.,2002. С. 231; Предпринимательское( хозяйственное) право / отв. ред. О.М. Олейник. Т 1. М., 1999. С. 614

${ }^{10}$ Суханова Е.А. Вступительная статья // Белов В.А. Ценные бумаги в российском гражданском праве / Под ред. Е.А. Суханова. М., 1996. С. 3.

${ }^{11}$ Верховенство права и проблемы его обеспечения в правоприменительной практике. М., 2009. С. 202.
} 


\section{Политика и общество 2 (98) • 2013}

ска и обращения ценных бумаг между его участниками $^{12}$. Однако и данный подход не дает «полного представления о комплексом характере отношений на рынке, его особенностях как такого сектора рыночной экономики, в котором государственное регулирование выступает в качестве необходимого элемента всей системы отношений ${ }^{13}$.

Определенные шаги к разрешению возникающих противоречий мы находим в исследовании Э.Э. Эмирсултановой, в котором автор приходит к выводу, что рынок ценных бумаг является полноценным звеном денежной системы, финансовым институтом, под которым понимается «совокупность правовых норм, регулирующих общественные отношения, складывающиеся на рынке ценных бумаг (государственном, муниципальном и корпоративном его секторах) по поводу образования, распределения и использования централизованных и децентрализованных фондов денежных средств посредством финансового инструмента - ценной бумаги». Финансовая сущность отношений, складывающихся в сфере рынка ценных бумаг, по ее мнению, заключается в том, что «рынок ценных бумаг представляет собой совокупность экономических отношений, объектом которых являются ценные бумаги как экономическое явление - форма движения (аккумулирования, распределения и использования) национального финансового капитала» ${ }^{14}$.

Бесспорно, что ценные бумаги в большой степени являются объектом частного права, нежели публичного, и сделки по их купле-продаже носят гражданско-правовой характер, как бесспорно и то, что рынок ценных бумаг, рассматриваемый как форма организации отношений между субъектами хозяйственного оборота, с одной стороны, и государством, выступающим в двух инстанциях, с другой, - в большей степени выступает объектом публичного права, прежде всего административного и частично финансового, нежели частного.

Представляется, что в достаточной мере отражает частноправовую и публично-правовую сущность рынка ценных бумаг определение, предложенное Е.В. По-

${ }^{12}$ Белов В.А. Государственное регулирование рынка ценных бумаг. учеб. пос. М., 2005. С. 14.

13 Предпринимательское право Российской Федерации /от вред. Е.П. Губин, П.Г. Лахно. М., 2000. С. 577.

14 Эмирсултанова Э.Э. Регулирование и контроль рынка ценных бумаг (финансово-правовой аспект). Диес... к.ю.н. M., 2008. C. 55, 56. качаловой. Она пишет: «Рынок ценных бумаг... - феномен, основанный на движении денежных средств, как капитала, которое (движение) оформляется посредством использования гражданско-правовых конструкций (договоров, соглашений и т.п.), однако имеет общую публичную цель - финансовое оздоровление и эффективное функционирование рыночной экономики, осуществляемое в рамках и в строгом соответствии с законодательством РФ посредством использования специально создаваемых денежных фондов (страховых, кредитных, резервных, бюджетных и т.п.) и выпуска ценных бумаг (государственных, муниципальных, корпоративных)» ${ }^{15}$.

Публично-правую сущность рынка ценных бумаг определяют его функции, которые в литературе разделяют на две группы: общерыночные и специфические.

К общерыночным функциям относят:

- коммерческую (получение прибыли от операции на рынке);

- ценовую (обеспечение процесса формирования рыночных цен);

- информационную (доведение до участников информации о объектах торговли);

- регулирующая (создание правил торговли и участие в ней).

К специфическим функциям относят:

- перераспределение денежных средств между отраслями и сферами рыночной деятельности;

- трансформацию сбережений (прежде всего населения) из непроизводительной в производительную форму;

- финансирование дефицита бюджетов различных уровней на неинфляционной основе;

- страхование ценовых и финансовых рисков (хеджирование).

Будучи структурным элементом финансового рынка, рынок ценных бумаг призван осуществлять такие фундаментальные функции, как аккумулирование и перераспределение капитала. «Роль и значение рынка ценных бумаг заключается в обеспечении притока капиталов для развития производства, неинфляционном привлечении ресурсов в бюджет, обеспечении стабильности финансовой системы. Для государства и корпоративных структур рынок ценных бумаг выступает источником необходимых ресурсов, а для инвесторов - сферой приложения капитала» ${ }^{16}$.

\footnotetext{
15 Финансовое право. Учеб / отв. ред. Н.И. Химичева. М., 2009. С. 743.

${ }^{16}$ Финансы. Денежное обращение. Кредит. Учебник / Под ред. Г.Б. Поляка. М., 2006. С. 440, 441.
} 
Внесение изменений в федеральный закон «О рынке ценных бумаг» от 22.04.1996 г. № 39-Ф3, принятие в 2001 году федеральных законов «Об организованных торгах», «О центральном депозитарии», издание нормативных правовых актов Минфина России, Федеральной службы по финансовым рынкам, - все это свидетельствует о том, что правовое регулирование рынка ценных бумаг, сохраняя преобладание частноправовой составляющей, одновременно, трансформировался в полноценный комплексный институт с существенной долей публичного, прежде всего административного, права.

Государство призвано в стать на защиту интересов инвесторов, в первую очередь миноритарных. Такая защита не может и не должна ограничиваться исключительно средствами гражданско-правовой охраны. В противном случае значительно возрастает риск возникновения «финансовых пирамид», с чем наша страна уже столкнулась в 90-е годы прошлого века. Предупреждение таких злоупотреблений на рынке ценных бумаг, как показывает мировой опыт, возможно только с использованием административно-правовых средств, предполагающих властное участие государства в соответствующих экономических отношениях.

Мировой опыт показывает, что рынок ценных бумаг тесным образом связан с состоянием национальной экономики и с процессами, происходящими на мировых финансовых рынках. Показательным примером служит ситуация в период мирового экономического кризиса 1929-1933 гг., когда фондовый кризис развивался синхронно с экономическим кризисом. Снижение темпов роста американской и европейской экономик, огромный дефицит государственного бюджета США в 1987г., паника, охватившая большое число участников фондового рынка, все это привело к глубокому падению курсов акций. Фондовые рынки чутко реагируют на политические события и валютные потрясения, как, например, на кризис в Персидском заливе, начавшийся в августе 1990 г. или девальвацию испанской песеты и португальского эскудо осенью 1992 г. Недавний экономический кризис был инициирован неполадками на финансовых рынках.

Приведенные факты свидетельствуют о том, что рынок ценных бумаг любой страны испытывает подъемы и падения под влиянием различного рода экономических и политических, внутренних и внешних факторов ${ }^{17}$. Российский фондовый рынок, имеющий короткую историю, не является в этом плане исключением, и пережил немало взлетов и падений.

Хотя современное состояние российского фондового рынка и оставляет желать лучшего, справедливости ради следует отметить, что на ряду показателей он продвинулся значительно вперед по сравнению с другими секторами финансового рынка. Например, капитализация российского рынка акций по отношению к ВВП составляет более $55 \%$ и приближается к среднемировому уровню (67\%). Увеличение емкости российского фондового рынка происходит и за счет облигаций, объем которых составляет $20 \%$ по отношению к ВВП, тогда как этот показатель в США, Японии, Германии находится в пределах 180-190\%. Причем рынок государственных облигаций в России в 3,5 раза превышает объем рынка корпоративных облигаций. При этом объем внутреннего российского рынка государственных облигаций по отношению к ВВП составляет $3,4 \%$. По этому показателю Россия занимает 39 место из 40 стран, по которым имеется соответствующая информация.

Имеется ряд нерешенных проблем, которые тормозят развитие фондового рынка и снижают его роль в инвестиционном процессе. Прежде всего, следует выработать государственную стратегию развития рынка ценных бумаг, в которой были бы определены приоритеты долгосрочной политики, способствующие тому, чтобы рынок ценных бумаг мог выполнять одну из важнейших макроэкономических задач - трансформировать сбережения в инвестиции. На сегодняшний день финансовый рынок России, неотъемлемой частью которого является рынок ценных бумаг, не способен «переварить» имеющиеся финансовые ресурсы ${ }^{18}$.

Российские фондовые рынки крайне болезненно реагируют на снижение кредитного рейтинга США и других развитых стран. По мнению аналитиков, российский рынок спекулятивный, почти весь во власти играющих «в короткую» хедж-фондов, долгосрочных инвесторов практически нет. Главная проблема российского фондового рынка - недостаточная активность частных инвесторов. 753 тысячи россиян совершают операции на фондовой бирже, но активных инвесторов в десятки раз меньше. Большие нормати-

\footnotetext{
17 Лялин В.А., Воробьев П.В. Рынок ценных бумаг: учеб. М, 2007. C. 368 .

18 Лялин В.А., Воробьев П.В. Рынок ценных бумаг: учеб. М, 2007. C. 378
} 


\section{Политика и общество 2 (98) • 2013}

вы достаточности собственных средств у финансовых компаний привели к тому, что за первое полугодие 2011 года с российского рынка ушло 70 профессиональных участников рынка ценных бумаг, в том числе в УрФО лицензии сдали 12 компаний. В мае 2011 года были утверждены новые нормативы, и собственные средства брокеров остались на уровне 35 миллионов рублей, вместо планируемых 50 миллионов. Представляется, что это позволит стабилизировать количество участников фондового рынка. По-прежнему, ощутимо влияют на деятельность профессиональных участников фондового рынка многие ограничения, связанные с аттестацией сотрудников и организацией работы персонала финансовых компаний в целом, побуждая порядком 70\% сотрудников заниматься подготовкой отчетности и внутренним учетом, и лишь 30\% непосредственно зарабатывают деньги. Некоторую избыточность ограничений уже не отрицают даже представители регулирующего органа. Одной из главных причин неактивности населения следует считать низкие доходы и низкую премию за риск на фондовом рынке, которая сегодня выше доходности банковских депозитов всего на 5-10\% при возможности потери до 80 вложений. При этом инвестиционный горизонт у россиянина, как правило, не превышает двух лет, а это слишком малый срок для существенной доходности при покупке акций. К тому же, неквалифицированный инвестор сегодня рискует потерять вложения в результате не только рыночного удешевления ценных бумаг, но и просто снятия их с торгов.

Представляется, что дальнейшее совершенствование финансово-правовой регламентации деятельности участников рынка ценных бумаг позволит обеспечить свободный доступ инвесторов на этот рынок и надежную защиту их законных интересов.

\section{Библиография:}

1. Давос проблем // Российская газета. 2012. 27 января.

2. Запольский С.В. Глобализация экономики: финансово-правовой аспект. // Финансовое право. 2011. № 11. С. 2 - 6.

3. Современный финансово-кредитный словарь / Под общ. ред. М. Г. Лагусты, П.С. Никольского. М.,2002.

4. Большой экономический словарь / Под ред. А.Н. Азрилиана. - 7-е изд. М., 2007.
5. Финансовый словарь. / Благодатин А.А., Лозовский Л.Ш., Райзберг Б.А. - М., 2009.

6. Большой юридический словарь / Под. ред. А.Я. Сухарева, В.Д. Зорькина, В.Е. Крутских - M, 1999.

7. Ершова И.В. Предпринимательское право. M., 2002.

8. Предпринимательское( хозяйственное) право / отв. ред. О.М. Олейник. Т 1. М., 1999.

9. Белов В.А. Ценные бумаги в российском гражданском праве / Под ред. Е.А. Суханова. М., 1996.

10. Верховенство права и проблемы его обеспечения в правоприменительной практике. М., 2009.

11. Белов В.А. Государственное регулирование рынка ценных бумаг. учеб. пос. М., 2005.

12. Предпринимательское право Российской Федерации /от вред. Е.П. Губин, П.Г. Лахно. М., 2000.

13. Эмирсултанова Э.Э. Регулирование и контроль рынка ценных бумаг ( финансово-правовой аспект). Диес... к.ю.н. М., 2008.

14. Финансовое право. Учеб / отв. ред. Н.И. Химичева. М., 2009. С. 743.

15. Авакян А.Р. Финансово-правовая природа рынка ценных бумаг // Государство и право. 2011. № 8. C. $101-112$.

16. Финансы. Денежное обращение. Кредит. Учбник / Под ред. Г.Б. Поляка.М., 2006.

17. Финансы, денежное обращение и кредит. Учебник / Под ред. В.К. Сенчагова, А.И. Архинова.М., 2004.C. 447.

18. Лялин В.А., Воробьев П.В. Рынок ценных бумаг: учеб. М, 2007. С. 368.

19. Инвесторы растерялись. // Российская газета. 2011. 9 августа.

20. Боты грозят бирже. // Российская газета. 2011. 6 октября.

21. Инвестор на бобах. // Российская газета. 2011. 13 октября.

\section{References (transliteration):}

1. Zapol'skiy S.V. Globalizatsiya ekonomiki: finansovo-pravovoy aspekt. // Finansovoe pravo. 2011. № 11 . S. $2-6$.

2. Sovremennyy finansovo-kreditnyy slovar' / Pod obshch. red. M. G. Lagusty, P.S. Nikol'skogo. M.,2002.

3. Bol'shoy ekonomicheskiy slovar'/ Pod red. A.N. Azriliana. - 7-e izd. M., 2007. 
Наследие и трансформации

4. Finansovyy slovar'. / Blagodatin A.A., Lozovskiy L.Sh., Rayzberg B.A. - M., 2009.

5. Bol'shoy yuridicheskiy slovar' / Pod. red. A.Ya. Sukhareva, V.D. Zor'kina, V.E. Krutskikh - M, 1999.

6. Ershova I.V. Predprinimatel'skoe pravo. M.,2002.

7. Predprinimatel'skoe( khozyaystvennoe) pravo / otv. red. O.M. Oleynik. T 1. M., 1999.

8. Belov V.A. Tsennye bumagi v rossiyskom grazhdanskom prave / Pod red. E.A. Sukhanova. M., 1996.

9. Verkhovenstvo prava i problemy ego obespecheniya v pravoprimenitel'noy praktike. M., 2009.

10. Belov V.A. Gosudarstvennoe regulirovanie rynka tsennykh bumag. ucheb. pos. M., 2005.

11. Predprinimatel'skoe pravo Rossiyskoy Federatsii /ot vred. E.P. Gubin, P.G. Lakhno. M., 2000.
12. Emirsultanova E.E. Regulirovanie i kontrol' rynka tsennykh bumag ( finansovo-pravovoy aspekt). Dies... k.yu.n. M., 2008.

13. Finansovoe pravo. Ucheb / otv. red. N.I. Khimicheva. M., 2009. S. 743.

14. Avakyan A.R. Finansovo-pravovaya priroda rynka tsennykh bumag // Gosudarstvo i pravo. 2011. № 8. S. $101-112$.

15. Finansy. Denezhnoe obrashchenie. Kredit. Uchbnik / Pod red. G.B. Polyaka.M., 2006.

16. Finansy, denezhnoe obrashchenie i kredit. Uchebnik / Pod red. V.K. Senchagova, A.I. Arkhinova.M., 2004.S. 447.

17. Lyalin V.A., Vorob'ev P.V. Rynok tsennykh bumag: ucheb. M, 2007. S. 368. 